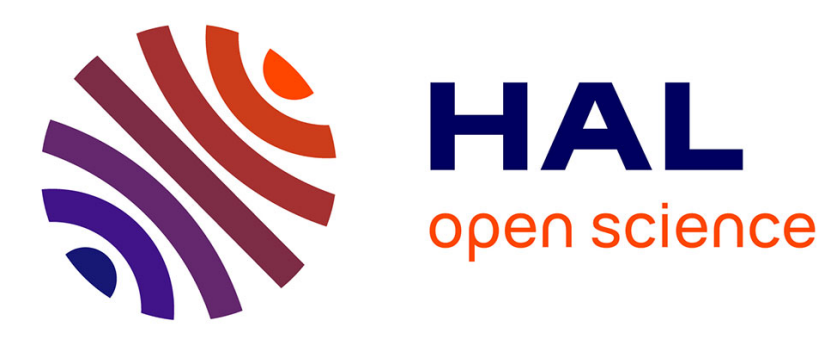

\title{
Optical storage in LiNbo3: Fe with selective erasure capability
}

\author{
J.-P. Huignard, J.-P. Herriau, F. Micheron
}

\section{To cite this version:}

J.-P. Huignard, J.-P. Herriau, F. Micheron. Optical storage in LiNbo3 : Fe with selective erasure capability. Revue de Physique Appliquée, 1975, 10 (6), pp.417-423. 10.1051/rphysap:01975001006041700 . jpa-00243939

\section{HAL Id: jpa-00243939 https://hal.science/jpa-00243939}

Submitted on 1 Jan 1975

HAL is a multi-disciplinary open access archive for the deposit and dissemination of scientific research documents, whether they are published or not. The documents may come from teaching and research institutions in France or abroad, or from public or private research centers.
L'archive ouverte pluridisciplinaire HAL, est destinée au dépôt et à la diffusion de documents scientifiques de niveau recherche, publiés ou non, émanant des établissements d'enseignement et de recherche français ou étrangers, des laboratoires publics ou privés. 


\title{
OPTICAL STORAGE IN $\mathrm{LiNbO}_{3}: \mathrm{Fe}$ WITH SELECTIVE ERASURE CAPABILITY
}

\author{
J.-P. HUIGNARD, J.-P. HERRIAU and F. MICHERON
}

Thomson CSF, Laboratoire Central de Recherches, BP 10, 91401 Orsay, France

\begin{abstract}
Résumé. - Après avoir analysé les différentes causes de déplacements macroscopiques des porteurs de charges photoexcités dans $\mathrm{LiNbO}_{3}$, on calcule les variations d'indice photoinduites correspondantes, pour les cas du cristal en circuit ouvert et en court-circuit. On montre dans le second cas qu'un effacement complet ou sélectif peut être obtenu par une méthode de soustraction cohérente.

Abstract. - After having analyzed the different causes of macroscopic displacements of photocarriers in $\mathrm{LiNbO}_{3}$, the corresponding photoinduced changes of refractive index are computed for the short-circuited and open circuited crystal. It is shown in the second case that total or selective erasure can be performed, using a coherent substraction technique.
\end{abstract}

1. Introduction. - Three dimensional storage using phase hologram recording in transparent media is a technique which allows high storage density and capacity, since the minimum bit size may be as small as the cube of the optical wavelength [1]. Photosensitive electrooptics belong to the most promissing class of three dimensional optical storage materials [2] : illumination causes mainly a change in refractive index, their spatial resolution is diffraction limited, they don't require any revealing process and they are reusable. Some of them require low recording light energy $\left(100 / \mu \mathrm{J} / \mathrm{cm}^{2}\right.$ for $\mathrm{K}(\mathrm{TaNb}) \mathrm{O}_{3}$ using a two photons process [3], $3 \mathrm{~mJ} / \mathrm{cm}^{2}$ for $\mathrm{Sr}_{0,75} \mathrm{Ba}_{0,25} \mathrm{Nb}_{2} \mathrm{O}_{6}$ [4]), or show strongly assymetric recording-erasure cycles, which allow multiple hologram superimpositions (more than 500 holograms superimposed in $\mathrm{LiNbO}_{3}: \mathrm{Fe}$ [5]).

In the most cases, the storage time is found experimentally equal to the dielectric relaxation time (some seconds to some months), and this is the reason why photoinduced change of refractive index is attributed to photoinduced electric fields, and not to polar defects reorientations or photoinduced dipole moments. Indeed, it was demonstrated that photocarriers excited from impurity centers can move on macroscopic distances in these crystals before being trapped, which generate space charge fields and refractive index changes via the electrooptic effect.

The carrier transport processes can be isotropic diffusion [6], or anisotropic diffusion in polar materials which give rise to a bulk photovoltaic effect [7], or drift under the influence of an applied field $[8,9]$, or combinations of these three effects. They generate a current in an external circuit connected to the crystal under illumination such as :

$$
J=q D \frac{\mathrm{d} n(x)}{\mathrm{d} t}+\alpha K I(x)+\left[\sigma_{0}+\beta I(x)\right] E(x)
$$

The diffusion current exists only for non uniform illuminations $I(x)$, which cause a gradient of photocarriers concentration $n(x)$.

The photovoltaic current is proportionnal to the absorbed light power $\alpha I(x)$ and can be measured only parallel to the polar axis of the crystal. The coefficient $K$ is odd function of the spontaneous polarization, and depends upon the nature and value of the impurity ions. The third term in the current $J$ accounts for the crystal conductivity and photoconductivity (photocarriers drifts) in presence of the electric field $E(x)$.

The field $E(x)$ inside the crystal is given by the electrical displacement $D$

$$
D=\int_{0}^{t} J \mathrm{~d} t
$$

and the photoinduced refractive index change is obtained using the appropriate electrooptic coefficients.

Using this model, we derive the operating conditions which provide the best use of the full dynamic range in refractive index changes, especially for holograms superimpositions and coherent erasures, in Fe doped $\mathrm{LiNbO}_{3}$ crystals $(0.015 \% \mathrm{Fe}, 3 \mathrm{~mm}$ thickness, reduced in $\mathrm{Ar}$ atmosphere for $50 \%$ absorption at $\lambda=514 \mathrm{~nm})$. 
2. Uniform illuminations of $\mathrm{Fe}$ doped $\mathrm{LiNbO}_{3}$ crystals. - The $\mathrm{LiNbO}$ ( crystal is first uniformely illuminated, and the short circuit current $i_{\mathrm{cc}}$ is measured between two electrodes perpendicular to the polar $c$ axis (Fig. 1a). Using eq. (1), $i_{\mathrm{cc}}$ is given by

$$
i_{\mathrm{cc}}=A \cdot \alpha K I
$$

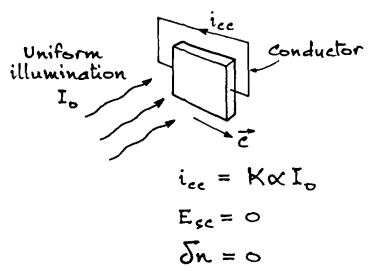

a) Short circut

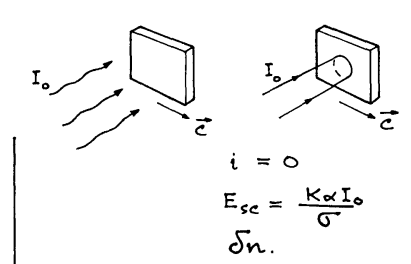

b) Open circuit
FIG. 1. - Uniform illumination of iron doped $-\mathrm{LiNbO}_{3}$ crystal and corresponding photocurrents $\left(i_{\mathrm{cc}}\right)$; photoinduced space charge field $\left(E_{\mathrm{sc}}\right)$; and photoinduced index change: Fig. $1 a$ : short circuit configuration; Fig. $1 b$ : open circuit configuration.

where $A$ is the electrodes area. Since no photovoltage can be generated in this short circuited crystal, it is expected from the previous model that the refractive index remains unchanged. The refractive index was measured using a low power $\mathrm{He}-\mathrm{Ne}$ laser and crossed polarizers, and no index change was observed under illuminations by an Ar laser at $\lambda=514 \mathrm{~nm}$, up to incident powers of $100 \mathrm{~mW} / \mathrm{cm}^{2}$ (the experimental arrangement limits the measure to index changes larger than $10^{-6}$ ). At higher powers, or long exposure times, an increasing scattering is observed in the transmitted beams, whereas no scattering effect can be detected with the same energy density, using an incoherent light source. This anomalous scattering effect under coherent illumination can be attributed to surface defects or bulk inhomogeneities : the coherent incident light beam is slighly scattered by the defects at the beginning of illumination, and the randomly scattered beams interfere inside the crystal. They cause a randomly non uniform repartition of illumination, which is therefore recorded as new refractive index inhomogeneities.

This effect limit to some $\mathrm{J} / \mathrm{cm}^{3}$ the energy density which can be absorbed during operations at room temperature. Nevertheless, the crystal recovers its low scattering state after heating at $200^{\circ} \mathrm{C}$ for some minutes: the increase in conductivity decreases the dielectric relaxation time $\tau$, therefore, complete erasure of all the recorded refractive index changes occurs by heating during times larger than $\tau$.

Considering now the arrangement of figure $1 b$, where the crystal is uniformely illuminated in open circuit, i. e. $J=0$. A space charge field $E_{\mathrm{sc}}$ can be developped by photovoltaic effect, which saturation value is given by

$$
E_{\mathrm{sc}}=-\frac{\alpha K I}{\sigma}
$$

where $\sigma$ is the conductivity under illumination. An homogeneous photoinduced change of refractive index is now observed, as previously reported by Glass [7], and the same scattering effects appear as shown in the short circuit configuration.

3. Non uniform illumination with holographic gratings. - Using the previous results, one can now deduce the spatial index distributions during hologram gratings recording, for open circuit and short circuit conditions. The spatial illumination repartition is

$$
I(x)=I_{0}(1+m \cos k x)
$$

where $k=2 \pi / \Lambda$, and $\Lambda$ is the fringe spacing. The fringes are perpendicular to the polar axis.

In the $\mathrm{LiNbO}_{3}: \mathrm{Fe}$ crystals used, both diffusions current at $\Lambda=10 \mu \mathrm{m}$ and photoconductivity current can be neglected compared to the photovoltaic current. This is not the case for $\mathrm{LiNbO}_{3}: \mathrm{Fe}$ crystals with higher ratios $\mathrm{Fe}^{3+} / \mathrm{Fe}^{2+}$ (less reduced crystals) in which photoconductivity must be taken into account.

Therefore, eq. $(1,2)$ reduce to

$$
j(x, t)=\alpha K I(x)+\sigma_{0} E(x, t)+\varepsilon \frac{\partial E(x, t)}{\partial t}
$$

open circuit configuration is described by the limiting condition :

$$
j(x, t)=0
$$

and solution for $E(x, t)$ is therefore

$E(x, t)=\frac{\alpha K I_{0}}{\sigma}(1+m \cos k x)\left(1-\exp -\frac{\sigma t}{\varepsilon}\right)$.

Both continuous and modulated terms in the holographic grating are recorded : during hologram superimpositions, the different continuous terms are added, which causes an increase of the average change of refractive index (and would contribuate to saturate the refractive index change in photoconductive crystals). Optical erasure by uniform illuminations causes erasure of the modulated component only, and increases the average change of refractive index.

In the short circuit configuration (Fig. $2 b$ ), the limiting condition is

$$
\int_{0}^{l} E(x, t) \mathrm{d} x=0
$$

solution of eq. (6) is therefore $(\Lambda \ll$ crystal length $l$ )

$$
E(x, t)=\frac{\alpha K I_{0}}{\sigma} m \cos k x\left(1-\exp -\frac{\sigma t}{\varepsilon}\right) .
$$

The continuous term in the holographic grating is no more recorded, and therefore, the short circuit configuration allows multiple hologram superimposition and provides a true optical erasure. This will be shown in the next section, for the particular case of coherent optical erasure. 


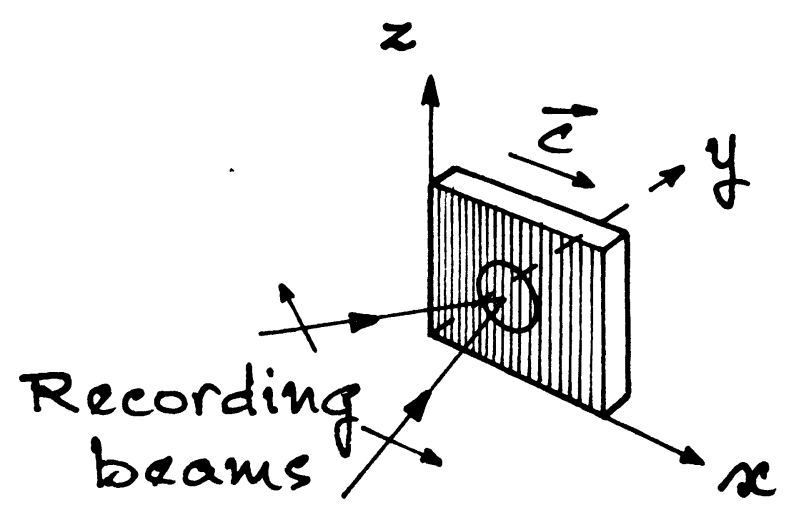

(a)

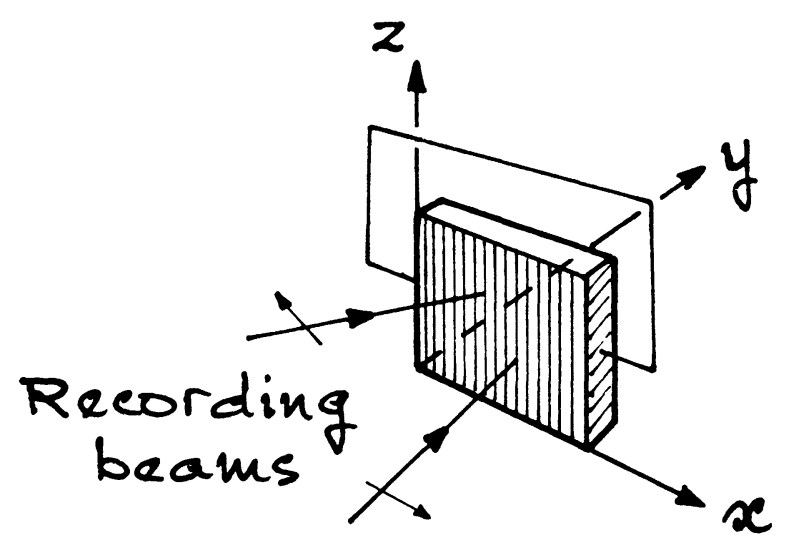

(b)

FIG. 2. - Spatial index change of refractive index after hologram grating recording: Fig. $2 a$ : open circuit configuration; Fig. $2 b$ : short circuit configuration.

4. Selective erasure of superimposed volume holograms. - Information pages can be superimposed at the same location of the storage medium by slightly changing the beam incidence outside of the Bragg selectivity range. Erasure of such recorded holograms is usually performed by uniform illumination of the storage crystal at the recording wave-length (or smaller) or by heating. Both of these techniques cause a bulk erasure process which apply indiscriminately to the different holograms and lead to limitations in applications of such a storage process [10]. Selective erasure of any stacked hologram or information bit is demonstrated by using a coherent image substraction method.

The storage crystal used for these experiments is iron doped and reduced $\mathrm{LiNbO}_{3}-0.015 \% \mathrm{Fe}$ - which shows a high resistance to optical erasure by uniform illumination - (assymetric Recording-Optical erasure cycle) [11]. The crystals having such a cycle are suitable for multiple storage, since the recording beams of a new hologram cause a weak erasure of the previously recorded ones in the same volume. The coherent erasure concept applies to such crystals providing a compact system with a greatly increased storage density and maintaining the versatility of erasure of any stacked hologram or bit in a page.
4.1 OPEN CIRCUIT RECORDING. - When recording the Fourier hologram of a transparent object having a nearly uniform spectrum, the refractive index change at spatial frequency $k$ is deduced from eq. (8), in open circuit recording conditions, using the linear electrooptic coefficients (Fig. 3a) :

$$
n(x, y, z)=n_{0}+\delta n \cos [k x+\varphi(x, y, z)]
$$

$n_{0}$ : bulk photoinduced index change developped by d. c. term of holographic pattern (low spatial frequency),

$\delta n$ : index modulation characteristic of fringes modulation (high spatial frequency).
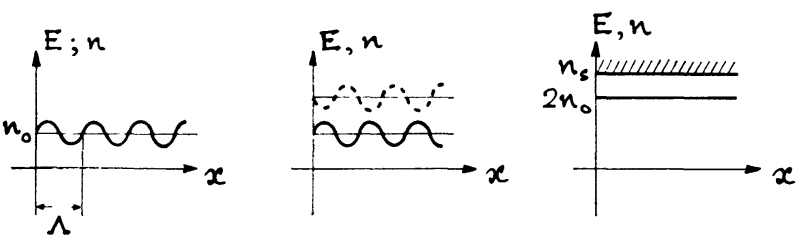

(a)
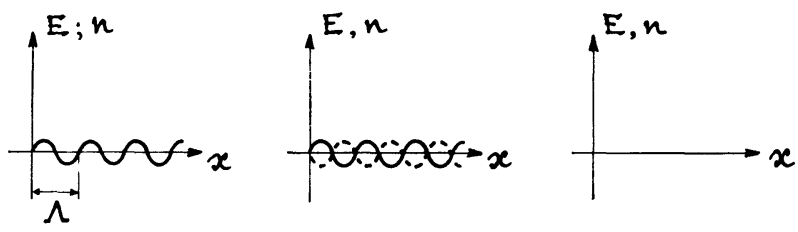

(b)

FIG. 3. - Spatial index change of refractive index after recording-coherent selective erasure cycle: Fig. $3 a$ : open circuit configuration; Fig. $3 b$ : short circuit configuration.

When now recording a complementary index modulation : $\delta^{\prime} n$ such as $\delta n+\delta^{\prime} n=0$, one can erase the corresponding modulation of the selected hologram. This is achieved by a second recording of the same object with introduction of $\pi$ shift on the reference wave. Light energy for coherent erasure cycle is exactly the same as used for recording.

The index change photoinduced during this second recording takes the form :

$$
n^{\prime}(x, y, z)=n_{0}-\delta n \cos [k x+\varphi(x, y, z)] \text {. }
$$

After several recording coherent erasure cycles the average index change is continuously increasing (contribution of the term $n_{0}$ ), and this should be a limitation of the number of cycles for a material having a limited index dynamic range $n_{\mathrm{s}}$ (Fig. $3 a$ ).

4.2 SHORT CIRCUIT RECORDING. - From the analysis performed in the previous section, recording and selective erasure operations should be done with the crystal short circuited. With such conditions eq. (10) shows that the index change is established around the original value (Fig. $3 b$ ).

$$
n(x, y, z)=\delta n \cos [k x+\varphi(x, y, z)]
$$


and by coherent erasure process, the new photoinduced change is :

$$
n^{\prime}(x, y, z)=-\delta n \cos [k x+\varphi(x, y, z)] .
$$

After such a Recording-Coherent erasure cycle, the initial index value is really recovered (Fig. $3 b$ ) and the number of cycles should not be limited. Nevertheless, the number of cycles is limited to a tenth by the scattering effect, which increases the noise after each cycle. The non recording of the d.c. terms of hologram patterns also provides an increase in the number of superimposed images since in practice a relatively low fringe modulation is used for high quality image reconstruction $(m \ll 1)$.

5. Experimental results. - Complete erasure of an information page can be performed using the coherent erasure process. Selective erasure of any information block or bit can be also achieved by recording of a partially masked transparency with $\pi$ shift. The common parts of the two transparencies are erased. This corresponds the logical operation Exclusive $O R$. Experimental confirmation is demonstrated in figure 4 (measured recording sensitivity : $250 \mathrm{~mJ} / \mathrm{cm}^{2} / \eta=1 \%$ ), which shows complete erasure, selective and only bit by bit erasure in a single recorded hologram.

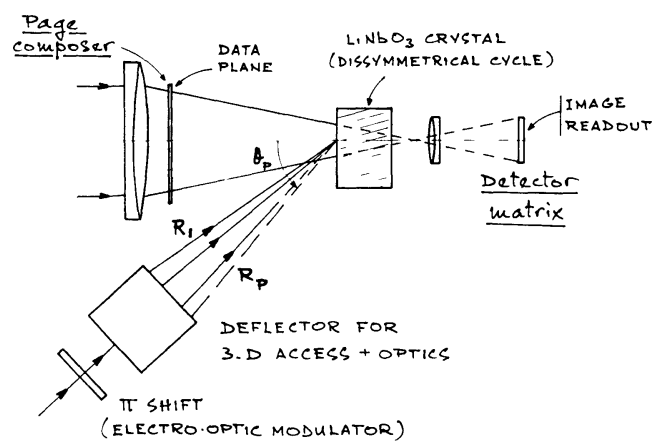

Fig. 4. - Selective erasure in a single recorded hologram.

Three holograms of the same binary page have been superimposed by changing the reference beam incidence on the crystal. These angle changes are provided by step mechanical translation of reference beam and converted into rotation by a lens (Fig. 5). The experimental sequence is the following :
- Recording of three stacked holograms of the same data plane (Bragg angles $\theta_{1}, \theta_{2}, \theta_{3}$ ) (hologram diameter : $1.7 \mathrm{~mm}$; Efficiency $\eta=1 \%$; Beam ratio : 13).

- Selective erasure of one single bit in the page (Fig. 6b).

- Repositionning of reference beam at Braggs angle $\theta_{2}$ and selective erasure in the page (Fig. 6b).

- Repositionning the reference beam on Bragg angle $\theta_{1}$, and complete erasure of the third hologram (Fig. 6b).

Figure 7 demonstrates the possibility of logical operations between two binary transparencies $A$ and $B$ (metallic grids for avoiding phase distorsion). In the particular situation where $B$ is a uniform object transparency $(B=1)$ the reconstructed image has a reversed contrast. The experimental sequence of figure 7 shows the logical operation $\overline{\bar{A}}+B$.

6. Comments. - For these experiments, precautions must be taken to avoid mechanical vibrations of the components. The laser stability and $\pi$ shift are continuously controlled by projection of a magnificated portion of the fringes on a vidicon with display on a TV monitor. The phase shift has been obtained either with an Electro-optic modulator, or by switching a Babinet plate between two positions. The problem encountered with our crystals is photoinduced scattering which rapidly degrades the signal to noise ratio of reconstructed images. After several Recording-Coherent erasure cycles, we observe the scattered light at the same level as that obtained by continuously reading one hologram with the reference beam during the same period of time. This effect limit actually in our crystals the number of superimposed images an selective erasure cycles to about 10 and the potential large dynamic range of the crystal is not used. As mentioned in [5] recording with heated could reduce the build up of this coherent scattering.

From system consideration, the ideal material would be a storage crystal with a completely dissymmetrical cycle and no photoinduced scattering. Information to be erased should be readed on the photodetector matrix and rewritten on the page composer for selective erasure. 
SELECTIVE ERASURE
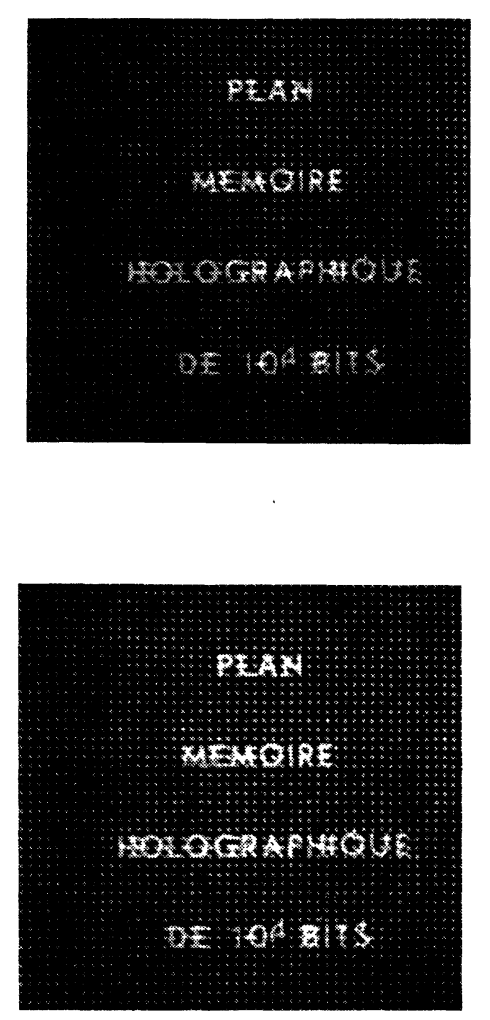

4

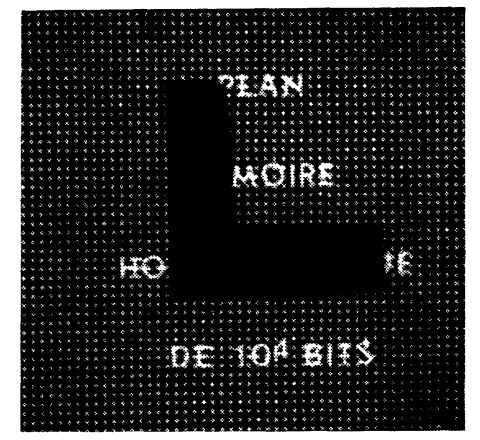

6

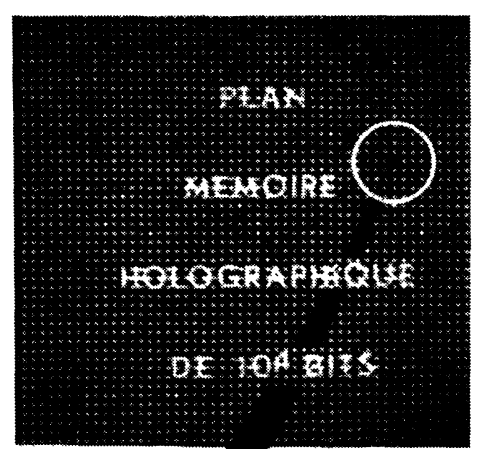

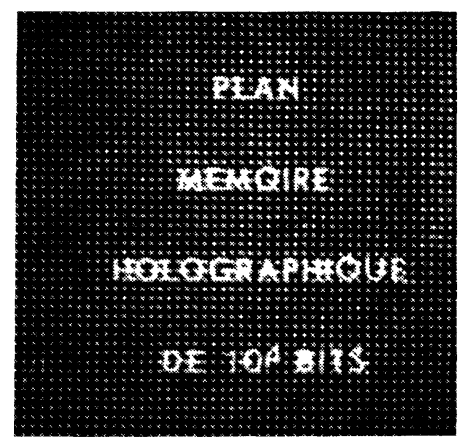

5

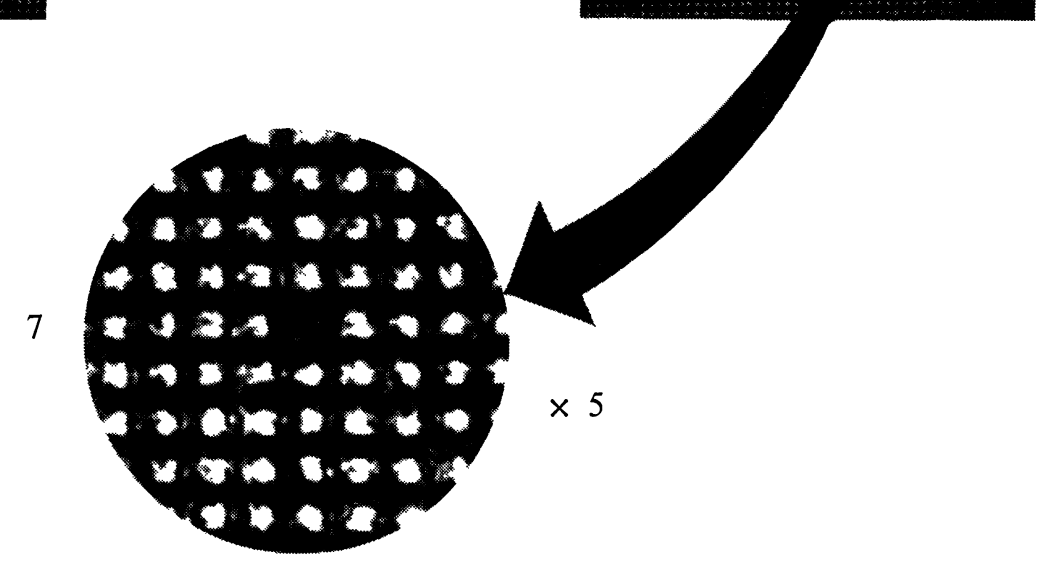

FIG. 5. - System configuration for selective erasure and processing in stacked holograms. 

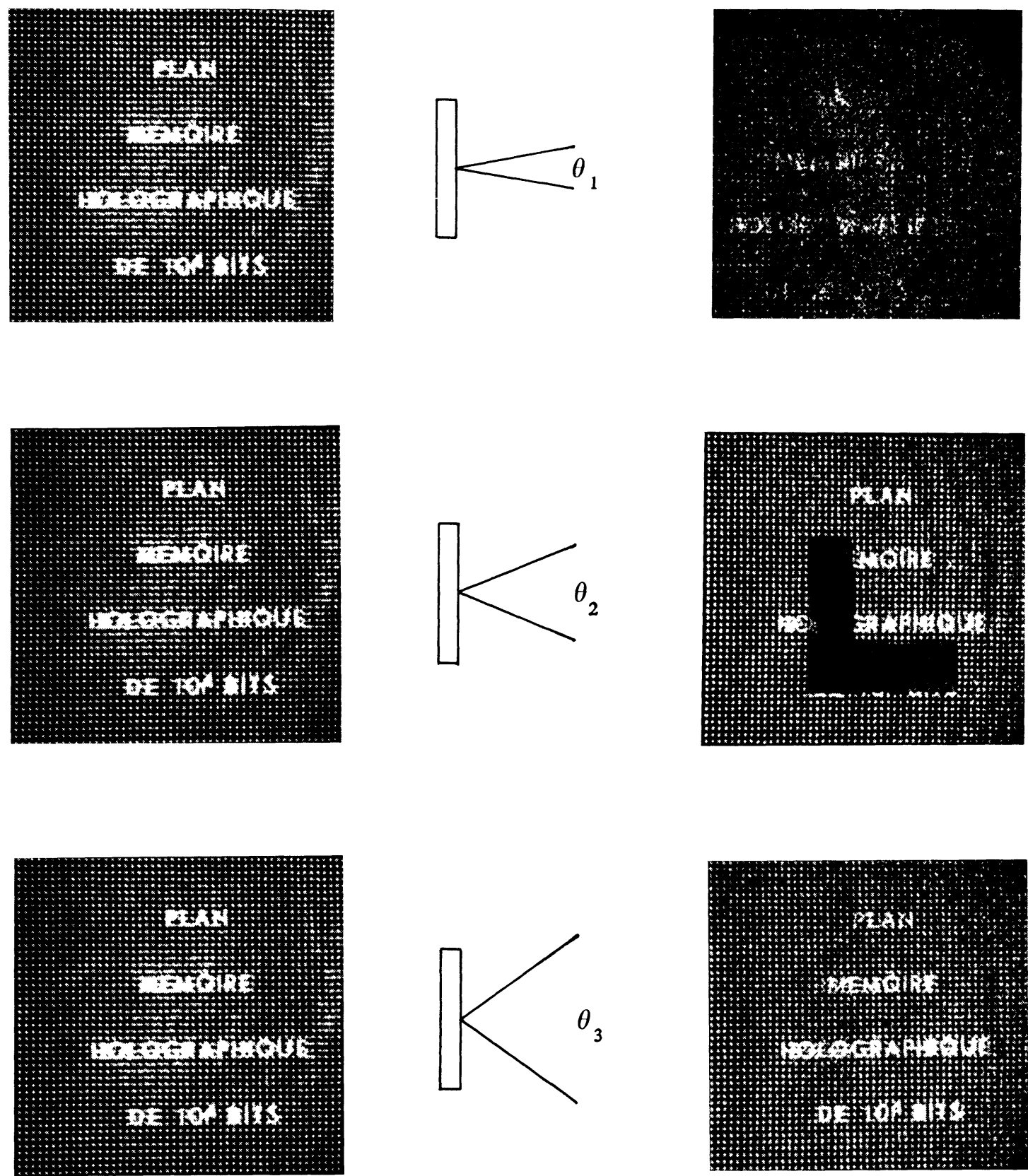

FIG. 6. - Selective erasure of stacked holograms : Fig. $6 a$ : images reconstruction from three stacked holograms ; Fig. $6 b$ : selective erasure in three stacked holograms with reference beam repositioning $\theta_{3}, \theta_{2}, \theta_{1}$, single bit erasure (Bragg angle $\theta_{3}$ ), partial erasure (Bragg angle $\theta_{2}$ ), complete erasure (Bragg angle $\theta_{1}$ ). 


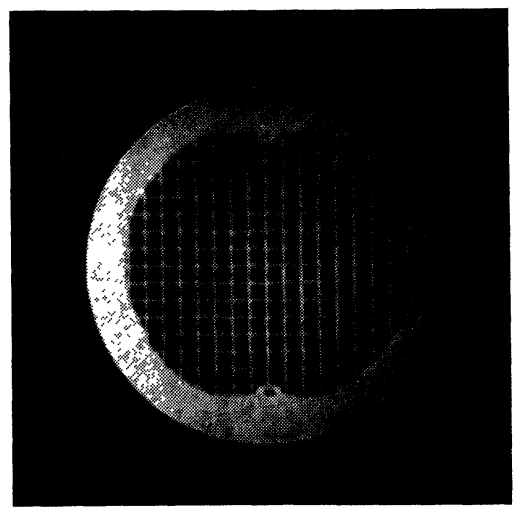

$\mathrm{A}^{\prime}$
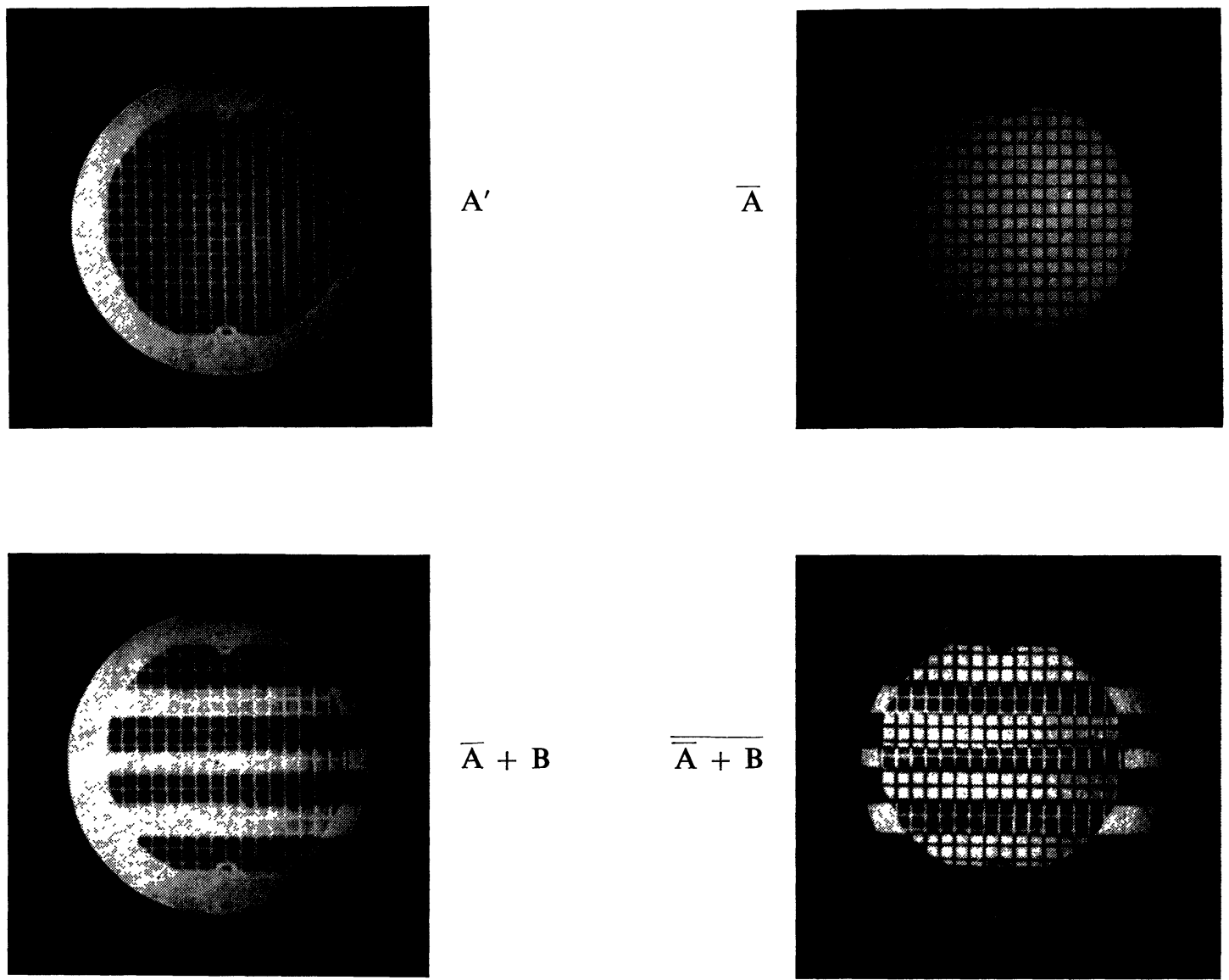

Fig. 7. - Logical operations between two binary transparencies $A$ and $B$ (operation $\overline{\bar{A}+B}=A \cdot \bar{B}$ ).

\section{References}

[1] Huignard, J. P., Micheron, F. and Spitz, E., In Optical properties of solids, Ed. B. O. Seraphin (North Holland) 1975.

[2] Glass, A. M., In : Photonics, Ed. M. Balkanski and P. Lallemand (Gauthier-Villars) 1975.

[3] Von der Linde, D., Glass, A. M. and Rodgers, K. F., Appl. Phys. Lett. 25 (1974) 155.

[4] Thaxter, J. B. and Kestigian, M., Appl. Opt. 13 (1974) 913.

[5] Staebler, D. L., Burke, W. J., Phillips, W. and Amodei, J. J., Appl. Phys. Lett. 26 (1975) 182.

[6] Amodei, J. J., Appl. Phys. Lett. 18 (1971) 22.
[7] Glass, A. M., Von der Linde, D. and Negran, T. J., Appl. Phys. Lett. 25 (1974) 233.

[8] Micheron, F., Rouchon, J. M. and Vergnolle, M., Appl. Phys. Lett. 24 (1974) 605.

[9] Kratzig, E. and Kurz, H., To be published in Ferroelectrics.

[10] D'Auria, L., Huignard, J. P., Slezak, Ch. and Spitz, E., Appl. Opt. 31 (1974) 788.

[11] Staebler, D. L. and Philips, W., Appl. Opt. 31 (1974) 788.

[12] Huignard, J. P., Herriau, J. P. and Micheron, F., Appl. Phys. Lett. 26 (1975) 256. 